\title{
A recombinant nucleocapsid protein-based indirect enzyme-linked immunosorbent assay to detect antibodies against porcine deltacoronavirus
}

\author{
Mingjun $\mathrm{SU}^{1)}$, Chunqiu $\mathrm{LI}^{1}$, , Donghua $\mathrm{GUO}^{1)}$, Shan WEI ${ }^{1)}$, Xinyu WANG ${ }^{1)}$, Yufei $\mathrm{GENG}^{1}$, Shuang $\mathrm{YAO}^{1)}$, Jing $\mathrm{GAO}^{1)}$, \\ Enyu $\mathrm{WANG}^{1)}$, Xiwen $\mathrm{ZHAO}^{1)}$, Zhihui $\mathrm{WANG}^{1}$, Jianfa WANG ${ }^{1}$, Rui $\mathrm{WU}^{1)}, \mathrm{Li} \mathrm{FENG}^{2)}$, and Dongbo $\mathrm{SUN}^{1) *}$ \\ ${ }^{1)}$ College of Animal Science and Veterinary Medicine, Heilongjiang Bayi Agricultural University, No. 5 Xinfeng Road, Sartu District, \\ Daqing 163319, P.R. China \\ 2)Division of Swine Infectious Diseases, National Key Laboratory of Veterinary Biotechnology, Harbin Veterinary Research Institute of \\ the Chinese Academy of Agricultural Sciences, No. 427 Maduan Street, Nangang District, Harbin 150001, P.R. China
}

(Received 9 September 2015/Accepted 3 December 2015/Published online in J-STAGE 13 December 2015)

ABSTRACT. Recently, porcine deltacoronavirus (PDCoV) has been proven to be associated with enteric disease in piglets. Diagnostic tools for serological surveys of PDCoV remain in the developmental stage when compared with those for other porcine coronaviruses. In our study, an indirect enzyme-linked immunosorbent assay (ELISA) (rPDCoV-N-ELISA) was developed to detect antibodies against PDCoV using a histidine-tagged recombinant nucleocapsid $(\mathrm{N})$ protein as an antigen. The rPDCoV-N-ELISA did not cross-react with antisera against porcine epidemic diarrhea virus, swine transmissible gastroenteritis virus, porcine group A rotavirus, classical swine fever virus, porcine circovirus-2, porcine pseudorabies virus, and porcine reproductive and respiratory syndrome virus; the receiver operating characteristic (ROC) curve analysis revealed $100 \%$ sensitivity and $90.4 \%$ specificity of the rPDCoV-N-ELISA based on samples of known status ( $\mathrm{n}=62$ ). Analyses of field samples $(n=319)$ using the rPDCoV-N-ELISA indicated that $11.59 \%$ of samples were positive for antibodies against PDCoV. These data demonstrated that the rPDCoV-N-ELISA can be used for epidemiological investigations of PDCoV and that PDCoV had a low serum prevalence in pig population in Heilongjiang province, northeast China.

KEY WORDS: ELISA, porcine deltacoronavirus, serum epidemiology

doi: 10.1292/jvms.15-0533; J. Vet. Med. Sci. 78(4): 601-606, 2016

Porcine deltacoronavirus (PDCoV) was first identified in a rectal swab collected in 2009 from a pig in Hong Kong, China, and it is related to avian and Asian leopard deltacoronaviruses that have been identified in apparently healthy wild animals $[6,22,23]$. Since first reported in swine in the U.S.A. in February 2014, PDCoV rapidly spread to other states in the U.S.A., as well as to Canada, and it caused significant economic losses in the swine industry [14, 16, 19-21]. Recently, PDCoV has been reported in the pig population from China and South Korea $[5,12]$. Hu et al. reported the cell culture isolation, serial propagation, and biologic and genetic characterizations of cell-adapted PDCoV strains [9]. Jung et al. reported that two PDCoV strains, OH-FD22 and OH-FD100, are enteropathogenic in gnotobiotic pigs [10]. Chen et al. revealed the pathogenicity of a plaque-purified PDCoV cell culture isolate and characterized PDCoV pathogenesis in neonatal piglets [3]. The accumulating reports

\footnotetext{
*Correspondence to: Sun, D., College of Animal Science and Veterinary Medicine, Heilongjiang Bayi Agricultural University, No. 5 Xinfeng Road, Sartu District, Daqing 163319, P.R. China. e-mail: dongbosun@126.com, Feng, L., Division of Swine Infectious Diseases, National Key Laboratory of Veterinary Biotechnology, Harbin Veterinary Research Institute of the Chinese Academy of Agricultural Sciences, No. 427 Maduan Street, Nangang District, Harbin 150001, P.R. China. e-mail: fl@hvri.ac.cn (C)2016 The Japanese Society of Veterinary Science

This is an open-access article distributed under the terms of the Creative Commons Attribution Non-Commercial No Derivatives (by-nc-nd) License $<$ http://creativecommons.org/licenses/by-nc-nd/4.0/>.
}

demonstrated that $\mathrm{PDCoV}$ is associated with diarrhea in pigs.

Porcine deltacoronavirus is an enveloped, positive-sense, single-stranded RNA virus that belongs to the genus of the subfamily Coronavirinae of the family Coronaviridae. The genome of PDCoV is approximately twenty-five kilobases in length, which is similar to those of other porcine coronaviruses, and it encodes four similar major structural proteins: the spike (S), envelope (E), membrane (M) and nucleocapsid (N) proteins $[13,15]$. Reports derived from other coronaviruses indicated that the $\mathrm{N}$ protein is highly conserved among different strains, and it is widely used as a diagnostic antigen for the development of serologic diagnostic tools $[1,8,11$, 17]. In the current study, a recombinant $N$ protein-based indirect enzyme-linked immunosorbent assay (ELISA) (rPDCoV-N-ELISA) was established to detect antibodies against porcine deltacoronavirus. Furthermore, the serum prevalence of PDCoV was investigated and analyzed using the rPDCoV-N-ELISA in Heilongjiang province, northeast China. Our aim was to provide a potential serological diagnostic tool for PDCoV.

\section{MATERIALS AND METHODS}

Antibody: Antisera against porcine epidemic diarrhea virus (PEDV), swine transmissible gastroenteritis virus (TGEV), porcine group A rotavirus (pGARV), classical swine fever virus (CSFV), porcine circovirus-2 (PCV-2), porcine pseudorabies virus (PRV), and porcine reproductive and respiratory syndrome virus (PRRSV) were kindly provided 
by the Division of Swine Infectious Diseases, National Key Laboratory of Veterinary Biotechnology, Harbin Veterinary Research Institute of the Chinese Academy of Agricultural Sciences. Monoclonal antibodies against histidine (His) and glutathione S-transferase (GST) tags were obtained from Tiangen Biotech Co., Ltd. (Beijing, China).

Synthesis and expression of the PDCoV $N$ gene: The nucleotide sequence of the entire $\mathrm{N}$ gene of PDCoV was obtained from the GenBank database at the National Center for Biotechnology Information website (accession no. JQ065043). The nucleotide sequence of the PDCoV N gene containing 5' and $3^{\prime}$ Bam HI and XhoI restriction sites, respectively, was synthesized based on the codon usage bias of Escherichia coli. The synthesized PDCoV N gene was cloned into the prokaryotic expression vectors $\mathrm{pET}-32 \mathrm{a}$ and pGEX-6P-1 so that it was tagged with His and GST, respectively. Recombinant plasmids were transformed into $E$. coli BL21 (DE3) cells, and then, $\mathrm{N}$ gene expression was induced using $1.0 \mathrm{mM} / l$ isopropyl $\beta$-D-thiogalactoside at $37^{\circ} \mathrm{C}$ for 4 $\mathrm{hr}$. Protein expression was analyzed by $12 \%$ sodium dodecyl sulfate-polyacrylamide gel electrophoresis (SDS-PAGE). Moreover, recombinant $\mathrm{N}$ proteins were purified according to the method described by Zhu et al. [24]. The recombinant $\mathrm{N}$ proteins of $\mathrm{PDCoV}$ were named $\mathrm{PPDCoV}-\mathrm{N}$.

Western blotting of the rPDCoV-N protein: Purified rPDCoV-N proteins with His or GST-tags were subjected to $12 \%$ SDS-PAGE and then transferred to a nitrocellulose (NC) membrane using a semi-dry transfer apparatus (Bio-Rad, Hercules, CA, U.S.A.). The NC membrane was blocked using $5 \%(\mathrm{w} / \mathrm{v})$ nonfat dried milk in phosphate-buffered saline (PBS) at $37^{\circ} \mathrm{C}$ for $1 \mathrm{hr}$ and then incubated with a mouse monoclonal antibody $(\mathrm{mAb})$ against the His-tag $(1: 1,000$ dilution in PBS) or a mouse monoclonal antibody (mAb) against the GST-tag $\left(1: 1,000\right.$ dilution in PBS) at $37^{\circ} \mathrm{C}$ for $1 \mathrm{hr}$. After washing three times with PBS, the membrane was incubated in PBS containing horseradish peroxidase (HRP)-conjugated goat anti-mouse IgG (1:5,000 dilution) at $37^{\circ} \mathrm{C}$ for $1 \mathrm{hr}$. After washing three times with PBS containing $0.05 \%$ Tween 20 (PBST), the membrane was incubated with enhanced chemiluminescence detection reagents (Biotopped, Beijing, China) at room temperature for $3 \mathrm{~min}$, and peroxidase-mediated luminescence was digitally captured using the Molecular Imager ChemiDoc XRS+ System (BioRad) and Image Lab software (Bio-Rad).

Screening of PDCoV-positive and PDCoV-negative sera: To collect PDCoV-negative and PDCoV-positive serum samples, the reverse transcription polymerase chain reaction (RT-PCR) was used to detect PDCoV in pig farms in Heilongjiang province. Briefly, rectal swab samples were collected from sows and piglets in diarrhea-affected and non-affected pig farms in Heilongjiang province from September 2014 to December 2014. Viral RNA in each sample was extracted using the TIANamp Virus RNA Kit (Tiangen Biotech Co., Ltd.). The cDNA was synthesized by (RNase $\mathrm{H}-)$ Moloney murine leukemia virus reverse transcriptase (Novoprotein Scientific Inc., Shanghai, China) according to the manufacturer's instructions. The PCR amplifications were conducted using primers specific for the PDCoV M gene (67F, 5'-ATCCTCCAAGGAGGCTATGC-3' and 560R, 5'-GCGAATTCTGGATCGTTGTT-3') according to the protocol described by Wang et al. [20]. Moreover, the serum samples, which were collected from PDCoV-positive and PDCoV-negative farms, were tested by western blot using rPDCoV-N proteins with His-tag and GST-tag, respectively. Briefly, purified rPDCoV-N proteins with a His-tag and GST-tag were subjected to $12 \%$ SDS-PAGE, respectively, and then transferred to an NC membrane. After blocking with $5 \%(\mathrm{w} / \mathrm{v})$ nonfat dried milk, the NC membrane was incubated with pig serum samples (1:200 dilution in PBS) at $37^{\circ} \mathrm{C}$ for $1 \mathrm{hr}$. After washing three times with PBS, the membrane was incubated in PBS containing HRP-conjugated rabbit anti-pig $\operatorname{IgG}\left(1: 5,000\right.$ dilution) at $37^{\circ} \mathrm{C}$ for $1 \mathrm{hr}$. The peroxidase-mediated luminescence was digitally captured using the Molecular Imager ChemiDoc XRS+ System (BioRad) and Image Lab software (Bio-Rad). The serum sample, which was collected from a PDCoV-positive and diarrheaaffected farm and can recognize purified $r P D C o V-N$ proteins with either a His-tag and GST-tag, was used as a positive control in the ELISAs. In addition, a total of 56 serum samples, which were collected from piglets before eating colostra in a PDCoV-negative and diarrhea-unaffected pig farm and can not recognize purified $\mathrm{rPDCoV}-\mathrm{N}$ proteins with either a His-tag and GST-tag, were used as negative sera in ELISAs.

rPDCoV-N-ELISA procedures: The conditions of the rPDCoV-N-ELISA, including the concentrations of coated antigen, blocking solution, sera and HRP-conjugated rabbit anti-pig IgG, as well as their incubation times, were optimized according to the $\mathrm{P} / \mathrm{N}$ value (the $\mathrm{OD}_{450}$ value of the $\mathrm{PDCoV}$-positive serum/the $\mathrm{OD}_{450}$ value of the PDCoV-negative serum). The best reaction conditions for the rPDCoVN-ELISA were as follows. ELISA plate (Costar, Corning, NY, U.S.A.) wells were coated with $1 \mu \mathrm{g} / \mathrm{m} l$ of purified Histagged $\mathrm{rPDCoV}-\mathrm{N}$ in $0.05 \mathrm{~mol} / l$ carbonate buffer $(\mathrm{pH} 9.6)$ at $4^{\circ} \mathrm{C}$ for $12 \mathrm{hr}$ and blocked with $5 \%$ skimmed milk at $37^{\circ} \mathrm{C}$ for $2 \mathrm{hr}$. After washing four times with PBST, $100 \mu \mathrm{l}$ of the test antisera, diluted 1:200, was added to the wells and incubated at $37^{\circ} \mathrm{C}$ for $1 \mathrm{hr}$. The plates were washed four times and incubated with $100 \mu l$ of HRP-conjugated rabbit anti-pig IgG diluted $1: 5,000$ in PBST at $37^{\circ} \mathrm{C}$ for $1 \mathrm{hr}$. After adding $100 \mu l$ of a $3,3^{\prime}, 5,5^{\prime}$-Tetramethylbenzidine (TMB) substrate solution and incubating at room temperature for $10 \mathrm{~min}$, the reaction was stopped by adding $50 \mu l$ of $2 \mathrm{M} \mathrm{H}_{2} \mathrm{SO}_{4}$, and the absorbance at $450 \mathrm{~nm}$ was measured.

Determination of the cut-off value for the rPDCoV-NELISA: The 56 PDCoV-negative serum samples were tested using the rPDCoV-N-ELISA. The reaction conditions were the same as those described for the rPDCoV-N-ELISA procedures. Each sample was tested three times, and the mean $\mathrm{OD}_{450}$ value was used for analysis. The result for each sample was converted into a percent reactivity $(\mathrm{PR})$ value based on the formula: $P R$ value $=\left[\right.$ the $\mid \mathrm{OD}_{450}$ value of the tested sample-the $\mathrm{OD}_{450}$ value of the negative control) $/ /\left(\right.$ the $\mathrm{OD}_{450}$ value of the positive control-the $\mathrm{OD}_{450}$ value of the negative control) $] \times 100 \%$. The PR cut-off value was determined as the mean PR value of the 56 PDCoV-negative sera $+2 \times$ the 
standard deviation.

Specificity test: To evaluate the specificity of the rPDCoVN-ELISA, antisera against PEDV, TGEV, PRoV, CSFV, PCV-2, PRV and PRRSV were tested using the rPDCoV-NELISA. The reaction conditions were the same as those used for the rPDCoV-N-ELISA procedures. The PR value of the test samples was calculated. Each sample was tested three times, and the mean PR value was used to determine whether the sample was positive or negative.

Validation of the rPDCoV-N-ELISA: To evaluate the feasibility of the rPDCoV-N-ELISA method, a total of 62 serum samples were randomly selected from six pig farms in Heilongjiang Province; 30 serum samples were collected from three diarrhea-free pig farms, and 32 serum samples were collected from three diarrhea-affected farms. These serum samples were tested using the rPDCoV-N-ELISA. Each sample was tested three times, and the mean PR value was used to determine whether samples were positive or negative. Meanwhile, 62 serum samples were subjected to western blotting using purified, GST-tagged rPDCoV-N. The western blotting procedure was the same as described above. To evaluate the cut-off value, sensitivity and specificity of the rPDCoV-N-ELISA, the receiver operating characteristic (ROC) curve was generated using the results of the western blotting as the standard for negative and positive determination. The statistical analysis was carried out by using SPSS software (Version 11.5 for windows, SPSS Inc., Chicago, IL, U.S.A.).

Detection of PDCoV in field samples by the PDCoV-NELISA: A total of 319 serum samples were collected from sows in 15 farms in Heilongjiang province from January 2014 to June 2015, of which 210 serum samples were collected from 9 farms without occurrence of diarrhea, and 109 serum samples were collected from 6 farms with occurrence of diarrhea. All serum samples were tested using the rPDCoV-N-ELISA. The reaction conditions were the same as those used for the rPDCoV-N-ELISA procedures. In the rPDCoV-N-ELISA, each sample was tested three times, and the mean PR value was used to determine whether a sample was positive or negative.

\section{RESULTS}

Expression, purification and identification of $r P D C o V-N$ : Prokaryotic expression of the synthesized $\mathrm{N}$ gene of PDCoV was conducted in the E. coli BL21 (DE3) strain using the vectors $\mathrm{pET}-32 \mathrm{a}$ (with a His-tag) and pGEX-6p-1 with a GST-tag. The results indicated that the recombinant $\mathrm{N}$ protein of PDCoV (rPDCoV-N) was successfully expressed in the vectors pET-32a with a His-tag $(\sim 56 \mathrm{kDa})$ (Fig. 1A) and pGEX-6p-1 with a GST-tag ( 64 kDa) (Fig. 1B). Furthermore, the rPDCoV-N protein was verified using anti-His-tag and anti-GST mAbs by western blotting (Fig. 1C).

Screening for PDCoV-positive and PDCoV-negative sera: Screening of PDCoV-positive sera was conducted by western blotting using the rPDCoV-N protein with a Histag and GST-tag as an antigen. The results revealed that one serum sample, named pZD-166, which was collected from one sow in a PDCoV-positive and diarrhea-affected farm in Heilongjiang province, exhibited a specific reaction with His-tagged and GST-tagged rPDCoV-N proteins (Fig. 2). The pZD-166 serum sample was used as a positive control when establishing the rPDCoV-N-ELISA procedures. Moreover, a total of 56 serum samples were collected from piglets, prior to eating colostra, in one diarrhea-unaffected farm in the Daqing area of Heilongjiang province, which was determined to be PDCoV-negative by RT-PCR (data not shown). All 56 serum samples were used to determine the cut-off value of the rPDCoV-N-ELISA, and the nSJZ-15 sample was used as a negative control when establishing the rPDCoV-N-ELISA procedures.

Cut-off value of the rPDCoV-N-ELISA: The 56 PDCoVnegative serum samples were tested using the rPDCoVN-ELISA according to previously established ELISA procedures. All test results were converted into the PR value according to the formula described previously (Fig. 3). The PR cut-off value of 48.5 (mean $+2 \times$ SD, 20.9+27.6) was used as the positive standard in the rPDCoV-N-ELISA.

Specificity of the rPDCoV-N-ELISA: In specific experiments, antisera against PEDV, TGEV, pGARV, CSFV, PCV2, PRV and PRRSV were used to test the specificity of the rPDCoV-N-ELISA. The results showed that the rPDCoV$\mathrm{N}$-ELISA did not cross-react with these antisera (PR value $<48.5$ ) (Fig. 4).

Validation of the rPDCoV-N-ELISA: To validate the rPDCoV-N-ELISA, a total of 62 serum samples were tested by western blotting using purified, GST-tagged rPDCoV-N and the rPDCoV-N-ELISA. The ROC curve indicated that sensitivity and specificity of the rPDCoV-N-ELISA were $100 \%$ and $90.4 \%$, respectively, when the optimized PR cutoff value was 48.9; the optimized PR cut-off value generated from the ROC curve was nearly in line with the PR cut-off value of 48.5 determined by negative sera (Fig. 5). Meanwhile, the area under ROC curve (ROC AUC) was 0.962, which further supported the effectiveness of the rPDCoV-NELISA (Table 1).

Detection of PDCoV in field samples using the rPDCoV$N$-ELISA: A total of 319 serum samples from 15 pig farms were tested by the rPDCoV-N-ELISA. The results indicated that $11.59 \%$ of samples (37/319) were positive for antibodies against PDCoV; for the farms without diarrhea, 3.33\% of samples (7/210) were positive for antibodies against PDCoV; for the farms with diarrhea, $27.52 \%$ of samples $(30 / 109)$ were positive for antibodies against PDCoV (Table 2).

\section{DISCUSSION}

In the current study, an indirect ELISA, rPDCoV-N-ELI$\mathrm{SA}$, which used recombinant $\mathrm{N}$ protein that was expressed from $E$. coli, was developed to detect antibodies against PDCoV. The PDCoV N protein shared $22.2 \%, 28.2 \%$ and 18.4\% amino acid identities with PEDV (strain CV777, accession no. DQ355221), TGEV (strain H, accession no. EU074218) and porcine respiratory coronavirus (PRCV) N proteins (strain ISU-1, accession no. DQ811787), respectively. Therefore, a cross-reaction between the $\mathrm{N}$ protein 

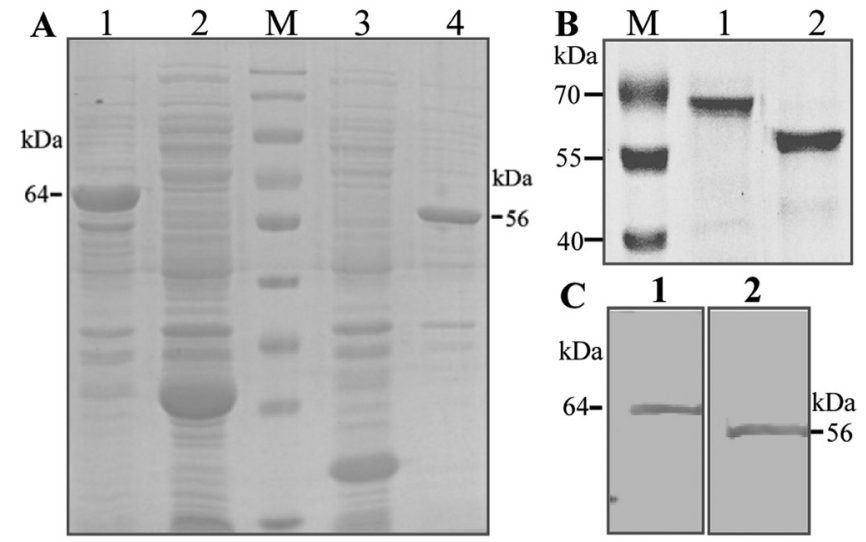

Fig. 1. Expression, purification and identification of the rPDCoV-N. A, Prokaryotic expression of the rPDCoV-N: Lane 1, the IPTG-induced recombinant bacteria of the rPDCoV-N with GST tag; Lane 2, the IPTG-induced recombinant bacteria of the pGEX-6p-1 vector; Lane M, PageRuler ${ }^{\mathrm{TM}}$ Prestained Protein Ladder (10k Da-170k Da); Lane 3, the IPTG-induced recombinant bacteria of the pET-32a vector; Lane 4, the IPTG-induced recombinant bacteria of the rPDCoV-N with His tag. B, Purification of the recombinant rPDCoV-N proteins: Lane M, PageRuler ${ }^{\mathrm{TM}}$ Prestained Protein Ladder (10k Da-170k Da); Lane 1, purified rPDCoV-N protein with GST tag; Lane 2, purified rPDCoV-N protein with His tag. C, Western blot of the recombinant rPDCoV-N protein: Lane 1, purified rPDCoV-N protein with GST tag; Lane 2, purified rPDCoV-N protein with His tag.

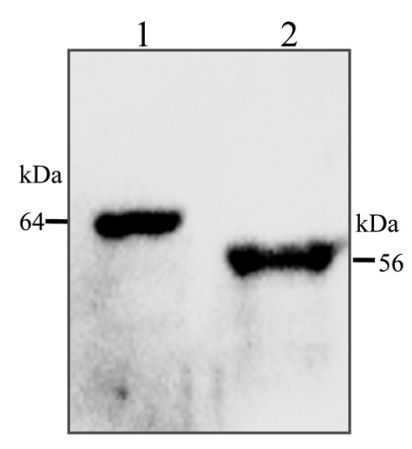

Fig. 2. Screening of positive and negative sera against the PDCoV.

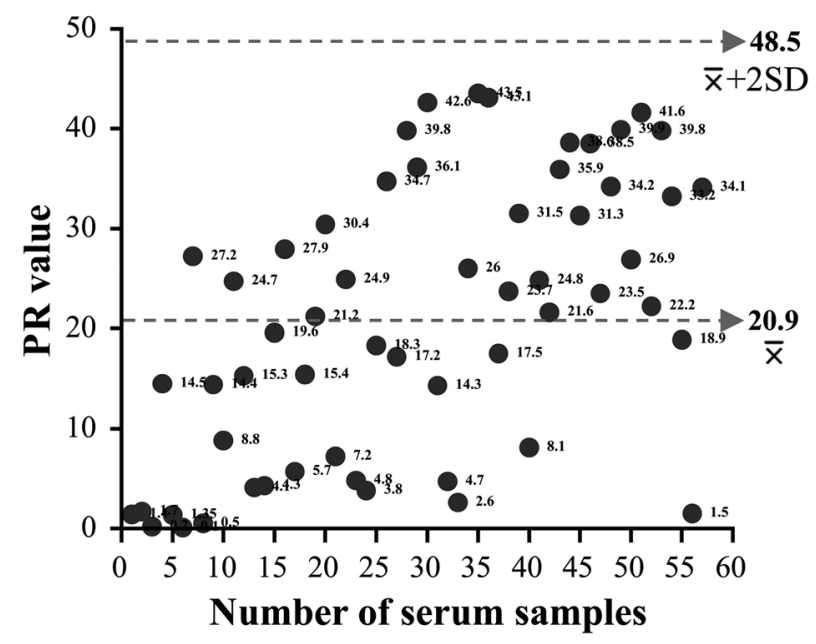

Fig. 3. Determination of the cut-off value of the rPDCoV-N-ELISA.

of the PDCoV and the $\mathrm{N}$ proteins from TGEV, PEDV and PRCV is unlikely. As expected, the PDCoV N protein did not cross-react with TGEV, PEDV, PRCV, PRoV, CSFV, PCV-2, PRV and PRRSV in the specificity assay. Our results are in line with those of an indirect anti-PDCoV IgG ELISA based on the putative S1 portion of the S protein, as described by Thachil et al. [17]. In addition, the $\mathrm{N}$ protein exhibited a high degree of conservation, $98.8-100 \%$ identities, among different PDCoV strains. Antón et al. reported that high levels of TGEV-specific antibodies could be induced by a combination of S-rosettes and the $\mathrm{N}$ protein [2]. These properties made the $\mathrm{N}$ protein suitable as a diagnostic antigen of $\mathrm{PDCoV}$ in an indirect ELISA, which was supported by other

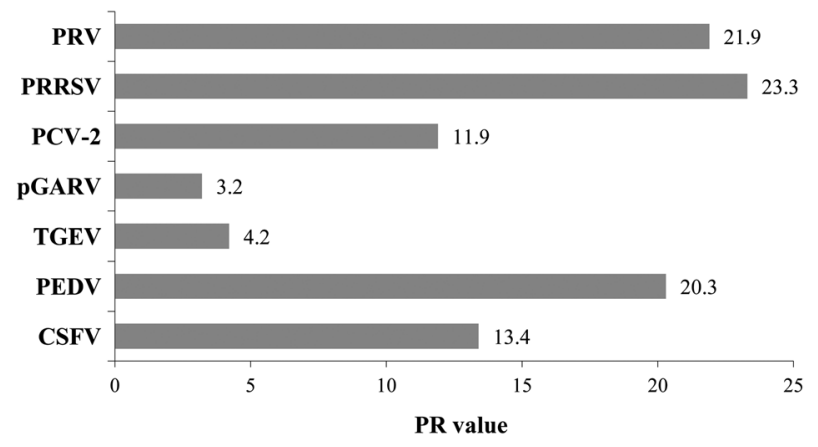

Fig. 4. Specificity test of the rPDCoV-N-ELISA.

coronavirus studies $[1,7,10,16]$.

Porcine deltacoronavirus is an emerging coronavirus; thus, a positive standard serum against PDCoV was not available in our study. However, positive serum against $\mathrm{PDCoV}$ is a key factor needed for the establishment of a rPDCoV-NELISA. In our study, to screen for PDCoV-positive serum, the PDCoV N gene was expressed using two prokaryotic expression vectors with different fusion tags: pGEX-6P-1 with a GST-tag and pET-32a with a His-tag. The PDCoV-positive sera from farms were validated when the samples showed a specific reaction with purified His-tagged and GST-tagged rPDCoV-N proteins, thereby eliminating all false-positive serum samples. Additionally, the PDCoV-negative serum samples were also strictly identified using a combination of the RT-PCR and western blotting using GST-tagged rPDCoV-N as an antigen. Moreover, the PR cut-off value of the rPDCoV-N-ELISA was determined by using PDCoVnegative serum samples. In our study, the introduction of 


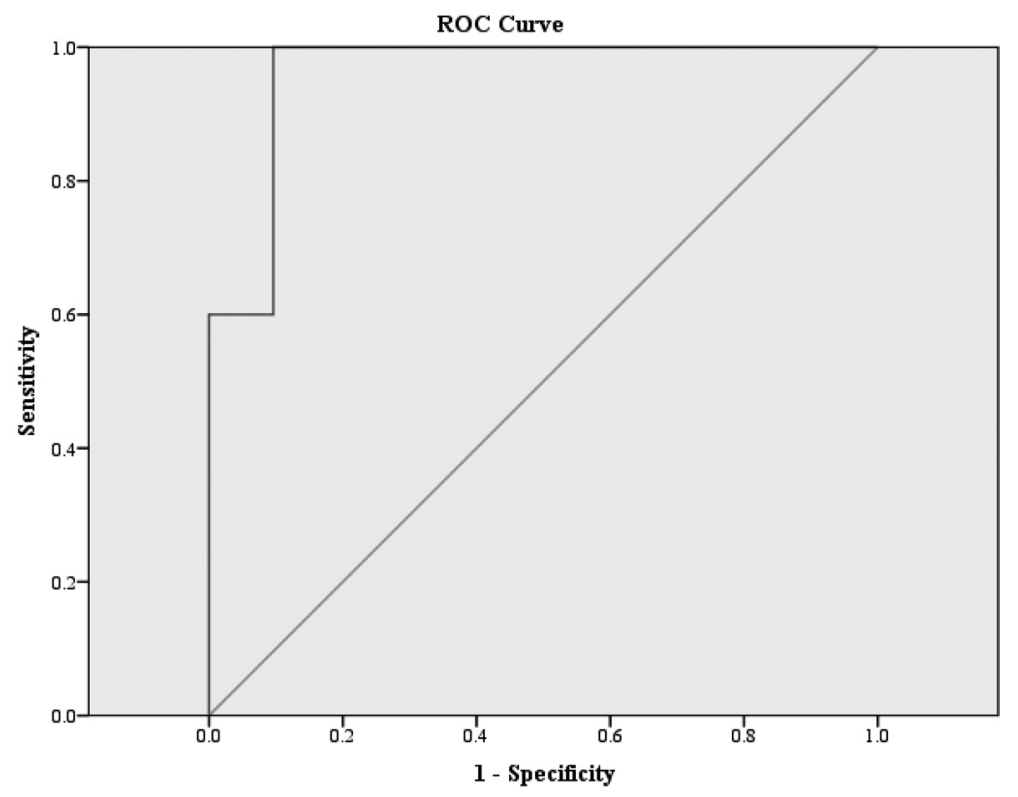

Fig. 5. The receiver operating characteristic (ROC) curve using western blotting as diagnostic standard.

Table 1. The area under the ROC curve

\begin{tabular}{ccccc}
\hline Area & Std. Error ${ }^{\text {a) }}$ & $\begin{array}{c}\text { Asymptotic } \\
\text { Sig }^{\text {b) }}\end{array}$ & \multicolumn{2}{c}{ Asymptotic 95\% confidence interval } \\
\cline { 3 - 5 } & & Lower bound & Upper bound \\
\hline 0.962 & 0.023 & 0.000 & 0.916 & 1.000
\end{tabular}

a) Under the nonparametric assumption, b) Null hypothesis: true area $=0.5$.

the PR value to the rPDCoV-N-ELISA reduced errors that resulted from different operation conditions, as was reported in a similar study [6].

Generally, a novel ELISA diagnostic method requires validation via a comparison with the same, or a similar, commercial ELISA kit. Although an indirect anti-PDCoV IgG ELISA based on the putative S1 portion of the spike protein has recently been reported by Thachil et al. [17], no ELISA kit was available for evaluation of the rPDCoV-N-ELISA that was established in our study. To evaluate the rPDCoVN-ELISA, comparison with the western blotting using GSTtagged rPDCoV-N as an antigen was carried by analysis of the receiver operating characteristic (ROC) curve. Compared with the western blotting, the rPDCoV-N-ELISA exhibited a relative specificity of $90.4 \%$ and a relative sensitivity of $100 \%$. Accumulating reports indicate that the $\mathrm{S}$ protein has a high degree of variability in the members of coronaviruses [4, 18]. Therefore, compared with S protein-based ELISAs, the rPDCoV-N-ELISA still has potential application value as a diagnostic antigen, because of the highly conserved nature. The rPDCoV-N-ELISA results of field samples indicated that $11.59 \%$ of samples were positive for antibodies against PDCoV. In our study, positive rate of the PDCoV antibodies in samples is similar to that reported by Thachil et al. [17]. It is suggested that an extensive serological investigation of
Table 2. Detection of the rPDCoV-N-ELISA in field samples

\begin{tabular}{lc}
\hline & Positive rate of PDCoV antibodies \\
\hline Non-diarrhea & $3.33 \%(7 / 210)$ \\
Diarrhea & $27.52 \%(30 / 109)$ \\
\hline Total & $11.59 \%(37 / 319)$ \\
\hline
\end{tabular}

the epidemiology of PDCoV in China should be performed in a future study.

In conclusion, the rPDCoV-N-ELISA has potential use for investigations of the epidemiology of PDCoV. Porcine deltacoronavirus has shown a low prevalence in limited serological investigations in Heilongjiang province, northeast China, and in the future, these results will need to be confirmed through more extensive serological investigation of PDCoV epidemiology.

ACKNOWLEDGMENTS. This work is partially supported by the State National Key Laboratory of Veterinary Biotechnology (grant no. SKLVBF201506), the National Natural Science Foundation of China (grant no. 31472209) and the Program for New Century Excellent Talents in Heilongjiang Provincial University (grant no. 1252-NCET-016).

\section{REFERENCES}

1. Abdelwahab, M., Loa, C. C., Wu, C. C. and Lin, T. L. 2015. Recombinant nucleocapsid protein-based enzyme-linked immunosorbent assay for detection of antibody to turkey coronavirus. J. Virol. Methods 217: 36-41. [Medline] [CrossRef]

2. Antón, I. M., González, S., Bullido, M. J., Corsín, M., Risco, C., Langeveld, J. P. and Enjuanes, L. 1996. Cooperation between 
transmissible gastroenteritis coronavirus (TGEV) structural proteins in the in vitro induction of virus-specific antibodies. Virus Res. 46: 111-124. [Medline] [CrossRef]

3. Chen, Q., Gauger, P., Stafne, M., Thomas, J., Arruda, P., Burrough, E., Madson, D., Brodie, J., Magstadt, D., Derscheid, R., Welch, M. and Zhang, J. 2015. Pathogenicity and pathogenesis of a United States porcine deltacoronavirus cell culture isolate in 5-day-old neonatal piglets. Virology 482: 51-59. [Medline] [CrossRef]

4. Chiou, H. Y., Huang, Y. L., Deng, M. C., Chang, C. Y., Jeng, C. R., Tsai, P. S., Yang, C., Pang, V. F. and Chang, H. W. 2015. Phylogenetic analysis of the spike (S) gene of the new variants of porcine epidemic diarrhoea virus in Taiwan. Transbound. Emerg. Dis. 2015: 22 10.1111/tbed.12357. [Medline]

5. Dong, N., Fang, L., Zeng, S., Sun, Q., Chen, H. and Xiao, S. 2015. Porcine Deltacoronavirus in Mainland China. Emerg. Infect. Dis. 21: 2254-2255. [Medline] [CrossRef]

6. Dong, B. Q., Liu, W., Fan, X. H., Vijaykrishna, D., Tang, X. C., Gao, F., Li, L. F., Li, G. J., Zhang, J. X., Yang, L. Q., Poon, L. L., Zhang, S. Y., Peiris, J. S., Smith, G. J., Chen, H. and Guan, Y. 2007. Detection of a novel and highly divergent coronavirus from asian leopard cats and Chinese ferret badgers in Southern China. J. Virol. 81: 6920-6926. [Medline] [CrossRef]

7. Guo, D. H., Sun, D. B., Wu, R., Yang, H. M., Zheng, J. S., Fan, C. L., Sun, B. and Wang, J. F. 2010. An indirect ELISA for serodiagnosis of cattle footrot caused by Fusobacterium necrophorum. Anaerobe 16: 317-320. [Medline] [CrossRef]

8. Hou, X. L., Yu, L. Y. and Liu, J. 2007. Development and evaluation of enzyme-linked immunosorbent assay based on recombinant nucleocapsid protein for detection of porcine epidemic diarrhea (PEDV) antibodies. Vet. Microbiol. 123: 86-92. [Medline] [CrossRef]

9. Hu, H., Jung, K., Vlasova, A. N., Chepngeno, J., Lu, Z., Wang, Q. and Saif, L. J. 2015. Isolation and characterization of porcine deltacoronavirus from pigs with diarrhea in the United States. $J$. Clin. Microbiol. 53: 1537-1548. [Medline] [CrossRef]

10. Jung, K., Hu, H., Eyerly, B., Lu, Z., Chepngeno, J. and Saif, L. J. 2015. Pathogenicity of 2 porcine deltacoronavirus strains in gnotobiotic pigs. Emerg. Infect. Dis. 21: 650-654. [Medline] [CrossRef]

11. Lee, H. K., Lee, B. H., Dutta, N. K., Seok, S. H., Baek, M. W., Lee, H. Y., Kim, D. J., Na, Y. R., Noh, K. J., Park, S. H., Kariwa, H., Nakauchi, M., Mai, Q., Heo, S. J. and Park, J. H. 2008. Detection of antibodies against SARS-Coronavirus using recombinant truncated nucleocapsid proteins by ELISA. J. Microbiol. Biotechnol. 18: 1717-1721. [Medline]

12. Lee, S. and Lee, C. 2014. Complete genome characterization of Korean porcine deltacoronavirus strain KOR/KNU14-04/2014. Genome Announc. 2: e01191-e14. [Medline] [CrossRef]

13. Li, G., Chen, Q., Harmon, K. M., Yoon, K. J., Schwartz, K. J., Hoogland, M. J., Gauger, P. C., Main, R. G. and Zhang, J. 2014. Full-length genome sequence of porcine deltacoronavirus strain
USA/IA/2014/8734. Genome Announc. 2: e00278-e14. [Medline] [CrossRef]

14. Ma, Y., Zhang, Y., Liang, X., Lou, F., Oglesbee, M., Krakowka, S. and Li, J. 2015. Origin, evolution, and virulence of porcine deltacoronaviruses in the United States. MBio 6: e00064. [Medline] [CrossRef]

15. Marthaler, D., Jiang, Y., Collins, J. and Rossow, K. 2014. Complete genome sequence of strain SDCV/USA/Illinois121/2014, a porcine deltacoronavirus from the United States. Genome Announc. 2: e00218-e14. [Medline] [CrossRef]

16. Marthaler, D., Raymond, L., Jiang, Y., Collins, J., Rossow, K. and Rovira, A. 2014. Rapid detection, complete genome sequencing, and phylogenetic analysis of porcine deltacoronavirus. Emerg. Infect. Dis. 20: 1347-1350. [Medline] [CrossRef]

17. Pradhan, S. K., Kamble, N. M., Pillai, A. S., Gaikwad, S. S., Khulape, S. A., Reddy, M. R., Mohan, C. M., Kataria, J. M. and Dey, S. 2014. Recombinant nucleocapsid protein based single serum dilution ELISA for the detection of antibodies to infectious bronchitis virus in poultry. J. Virol. Methods 209: 1-6. [Medline] [CrossRef]

18. Thachil, A., Gerber, P. F., Xiao, C. T., Huang, Y. W. and Opriessnig, T. 2015. Development and application of an ELISA for the detection of porcine deltacoronavirus $\mathrm{IgG}$ antibodies. PLoS ONE 10: e0124363. [Medline] [CrossRef]

19. Vlasova, A. N., Marthaler, D., Wang, Q., Culhane, M. R., Rossow, K. D., Rovira, A., Collins, J. and Saif, L. J. 2014. Distinct characteristics and complex evolution of PEDV strains, North America, May 2013-February 2014. Emerg. Infect. Dis. 20: 1620-1628. [Medline] [CrossRef]

20. Wang, L., Byrum, B. and Zhang, Y. 2014. Detection and genetic characterization of deltacoronavirus in pigs, Ohio, U.S.A., 2014. Emerg. Infect. Dis. 20: 1227-1230. [Medline] [CrossRef]

21. Wang, L., Byrum, B. and Zhang, Y. 2014. Porcine coronavirus HKU15 detected in 9 US states, 2014. Emerg. Infect. Dis. 20: 1594-1595. [Medline] [CrossRef]

22. Woo, P. C., Lau, S. K., Lam, C. S., Lai, K. K., Huang, Y., Lee, P., Luk, G. S., Dyrting, K. C., Chan, K. H. and Yuen, K. Y. 2009. Comparative analysis of complete genome sequences of three avian coronaviruses reveals a novel group 3 c coronavirus. $J$. Virol. 83: 908-917. [Medline] [CrossRef]

23. Woo, P. C., Lau, S. K., Lam, C. S., Lau, C. C., Tsang, A. K., Lau, J. H., Bai, R., Teng, J. L., Tsang, C. C., Wang, M., Zheng, B. J., Chan, K. H. and Yuen, K. Y. 2012. Discovery of seven novel Mammalian and avian coronaviruses in the genus deltacoronavirus supports bat coronaviruses as the gene source of alphacoronavirus and betacoronavirus and avian coronaviruses as the gene source of gammacoronavirus and deltacoronavirus. J. Virol. 86: 3995-4008. [Medline] [CrossRef]

24. Zhu, Q., Guo, D., Feng, L. and Sun, D. 2013. Expression and Purification of the scFv from hybridoma cells secreting a monoclonal antibody against S PROTEIN of PEDV. Monoclon. Antib. Immunodiagn. Immunother. 32: 41-46. [Medline] [CrossRef] 